\title{
Consideration of Subjective Effects of Virtual Reality Implementation upon Designing of Educational Systems
}

\author{
Mikhail Vladimirovich Voropaev ${ }^{1 *}$, Bogdan Leonidovich Legostaev², Alla Ganicheva ${ }^{3}$, \\ Polina Iosifovna Arapova ${ }^{3}$, Natalia I. Getmanenko ${ }^{4}$ \\ ${ }^{1}$ Moscow City University, Moscow, Russia \\ ${ }^{2}$ Moscow Center for Educational Quality, Moscow, Russia \\ ${ }^{3}$ Moscow City Pedagogical University, Moscow, Russia \\ ${ }^{4}$ Charles University, Prague, Czech Republic
}

\begin{abstract}
This article studies the effects of application of digital environment with extended number of variables for assessment of learning activity by teachers and principals. In the case analyzed in this article, the virtual reality (VR) technologies were implemented into schools. The main method of studies is structured survey with participants in the innovation project. The main experimental results presented in this article are the necessity to account for existing business processes in educational entities, cardinal rearrangement of learning process based on the principle of individual learning, integration of all applied assessment systems, formation of special module providing analysis of overall data combination. Implementation of VR technologies should be preceded by multi-aspect preparation of personnel, covering both technological aspects and variation of occupational position. This article discusses opportunities of efficient usage of VR technologies in learning process.
\end{abstract}

\section{Introduction}

All educational systems in this or that way assess educational achievements. It is quite natural that in modern managerial practices based on digital tools, the sphere of control and assessment varies qualitatively: in particular, more and more variables are exposed to measurements and assessment. This article is not aimed at analysis of overall range of formation of feedback in the systems of education management. The subject is the studies of effects originated by online access for teachers to numerous variables of measurement and assessment of students' activities.

The presented materials are oriented at correction of initial theoretical concepts of implementation and development of digital systems in education.

In scientific pedagogical publications there is an established tradition to describe the phenomenon of teachers' assessment. If a mark is interpreted sufficiently uniformly, as a formal (conventionally symbolic) quantitative result of assessment learning achievements,

* Corresponding author: voropmv@gmail.com 
then the understanding of assessment process differs significantly. In Russian psychology and pedagogics, analysis of assessment issues in learning process was conventionally related (starting from the 1930-s) with the influence of assessment on personal development of learning activity of a student. Another trend of analysis of assessment issues was related with didactics and pedagogical management. Various aspects of this problem were discussed by Mikhailychev [1], Polonskii [2], Bespalko [3], and others. It should be mentioned that Bespalko pioneered allocation of automated elements in the management of learning process [3].

At current stage of education digitalization, all teaching technologies are significantly varying, including diagnostics procedures. They become more efficient, require for less time and less organizational consumptions from a teacher, thus allowing to use them continuously and individually, and not frontally and episodically as previously.

Scientific problematics of investigation into VR technologies in educational sphere are very wide. The most urgent topics related with VR vary from the technical aspects of immersive effects to the issues of teaching in primary school ([4-20], [21, 22], [23, 24]).

Unfortunately, no publications were available devoted to such narrow issue as peculiarities of application and implementation of VR systems as tools of assessment. The authors discussed only certain aspects of this issue in relation to other problems. Torre, while describing virtual schools, mentioned that it was difficult to assess skills of high level using VR technologies [25]. Roussou, Oliver, and Slater in their work mentioned that in VR environment different students' positions could exist: both passive and active; and technogenic actors (NPC analog in games) providing support and promoting development of students' self-assessment could support education conceptualization in different degree [26].

\section{Methods}

This work was aimed at investigation into primary effects of VR technologies as a tool of knowledge assessment. The study was performed during pilot implementation (2019) of the VR system into educational entities of Moscow for teaching certain subjects. The system interface provided to a teacher information not only about results of fulfillment or nonfulfillment of assignment but also a wide list of supplemental variables, namely:

1. Progress of solution to certain problem was visualized in the form of selection of specific track in logical diagram, reflecting possible strategies and tactics of the problem solution. The teacher obtained a diagram with all variants of solution, which were marked as conventional, optimum, and others.

2. Time consumed for solving of each stage of assignment.

3. Number of returns.

4. Number of requests for hints.

5. Committed errors.

On the basis of these data, the system proposed characteristic of students' learning style. The system developers assumed that availability of such generalized markers would allow to more exactly use teachers' assessment. At the same time, addition of opportunity to process such indicators would allow to use the system for formation of more general level of teachers' assessment system: at the level of educational space including several educational entities.

Structured surveys were used to study the effects of the system implementation. The surveys were oriented at determination of the following types of questions: general attitude of respondent to IT sphere, including experience of operation with computer services, attitude to VR technologies, attitudes to modern education and basic and professional plans of respondent in occupational sphere, total assessment of tested system including effects, forecast of its application in educational mainstream. 19 teachers were surveyed, participating in the system testing, 6 principals of educational entities, and 7 managers of 
regional agencies of education management, who were involved in development and verification of the system.

\section{Results and Discussion}

Surveying was carried out two months after startup and adjustment of the system. All surveyed persons had sufficient experience of operation with computer services. Most teachers and principals could be considered as qualified users. The second group of the respondents was comprised of IT specialists: software developers, system administrators, and others.

Analysis of answers demonstrated that in general all respondents positively appreciated IT technologies as an inherent portion of modern life. Without exceptions, all teachers identified themselves as qualified experts, everybody was positive about their work. Herewith, the informative communication technologies were accepted by them as a tool with limited set of opportunities, and the VR technologies - as having even narrower set of possible variants. IT specialists in their surveys were by far less satisfied with their work. Educational problems as such were accepted by them as secondary, sometimes with irritation.

All teachers mentioned that the system provided very interesting results. Their answers could be approximately subdivided into three groups. The first group (four teachers) actually did not use the obtained data. Nine teachers described their experience, comprised of accounting for certain elements of the obtained data. And only six teachers systematically used the information. Exactly these respondents noticed that, using this information, the work with students became simpler, however, everybody stated that the system was incomplete, should be adjusted and cover all remaining spheres of learning process.

Principals and managerial staff of educational entities gave in general sufficiently consolidated assessment. Firstly, they stated objectively some improvement of students' performances and significant increase in amount of solved problems requiring for nonstandard approach. Secondly, they confirmed the fact that many teachers did not use opportunities provided by the system. And thirdly, the most creative teachers stated that the informative elements should be converted into a system with controlling modules.

The obtained results make it possible to conclude as follows:

1. Implementation of elements of VR technology into learning process has constrained positive effect stipulated by various reasons. On the one hand, it is obvious that the main technological and business processes in educational system should be balanced, and application of separate innovation elements does not increase qualitatively its efficiency. Presumably, VR should be used in totally individualized educational environment.

2. There are no contradictions between conventional assessment of learning activities by teacher and supplemental information presented by VR interface.

3. Application of data presented by VR modules for managers at the level of educational entity and region requires for development of supplemental analytical module.

4. Implementation of VR technologies should be accompanied by preparation of personnel, moreover, the preparation content should not be restricted by technical aspects of working with program.

\section{Conclusion}

The presented results have been obtained in sufficiently specific conditions of educational system of megalopolis (Moscow). However, it is possible to assume that "spotted", fragmentary usage of VR technology can only partially increase the efficiency of learning process. As can be judged by analysis of structured surveys of people who can be considered 
as experts in the field of education, the opportunity to develop VR technologies is creation of semi-automated systems supporting combined learning in the frames of educational entity. Only in this case it is possible to expect for qualitative growth of the extent of individual learning.

Implementation of innovations of such type assumes not only preparation of personnel with regard to instrumental skills, but also serious variation of teachers' occupational position, reorientation to purposes of development of personal and intelligent qualities of students.

\section{References}

1. E.A. Mikhaylychev, Conceptual pedagogical diagnostics: formation, achievements, problems and development prospects: monograph (Taganrog State Pedagogical Institute, Taganrog, 2007)

2. V.M. Polonsky, Assessment of knowledge of students (Znanie, Moscow, 1981)

3. V.P. Bespalko, Components of pedagogical technology (Pedagogy, Moscow, 1989)

4. A. Aierbe, E. Oregui, I. Bartau, Education Review 36, 100 - 116 (2019)

5. M. Al-Sada, K. Jiang, S. Ranade, Virtual Reality 24, 191-209 (2020)

6. M. Berti, Italian Open Education: Virtual Reality Immersions for the Language Classroom, in New case studies of openness in and beyond the language classroom (2019)

7. S.P.R.K. Bhama, V. Hariharasubramanian, O.P. Mythili, Virtual Reality 24, 163-173 (2020)

8. J. Birt, M. Cowling, Assessing mobile mixed reality affordances as a comparative visualization pedagogy for design communication. Research in Learning Technology 26 (2018)

9. B. Bortnik, N. Stozhko, I. Pervukhina, A. Tchernysheva, G. Belysheva, Research in Learning Technology 25 (2017)

10. R. Casañ-Pitarch, Digital Education Review 31, 80 - 92 (2017)

11. D. Checa, A. Bustillo, Advantages and limits of virtual reality in learning processes: Briviesca in the fifteenth century. Virtual Reality 24 151-161, (2020). Retrieved from: https://doi.org/10.1007/s10055-019-00389-7

12. M. Ellis, P. Anderson, Journal of Instructional Pedagogies 6, 1-12 (2011)

13. C., Faria E. Guilherme, J. Pintassilgo, M.J. Mogarro, A.S. Pinho, M. Baptista, I. Chagas, C. Galvão, Digital Education Review 36, 85-99 (2019)

14. H. Gaspar, L. Morgado, H. Mamede, Virtual Reality 24, 319-341 (2020)

15. R. Godwin-Jones, Language Learning \& Technology 8(3), 9-14 (2004)

16. M.C. Lam, M.J. Sadik, N.F. Elias, Virtual Reality (2020)

17. G. Liu K. Lu, Computer Animation and Virtual Worlds 24(2), (2012)

18. F. Morasse, E. Vera-Estay, M.H. Beauchamp, Virtual Reality (2020)

19. L. Rebenitsch, C. Owen, Virtual Reality (2020)

20. M. Rosselló, C. Pinya, Digital Education Review 31, 20 - 38 (2017)

21. S. Sejdiu, Digital Education Review 32, 60 - 72 (2017)

22. K. Su, S. Chen, P. Lin, Virtual Reality 24, 241-254 (2020)

23. N. Vasilevski, J. Birt, Research in Learning Technology 28 (2020)

24. M. Zahabi, A.M. Abdul Razak, Virtual Reality (2020) 
25. D. Torre, International Journal of E-Learning \& Distance Education 27(1), (2020) Available at: http://www.ijede.ca/index.php/jde/article/view/838/1498

26. M. Roussou, M. Oliver, M. Slater, Virtual Reality 10, 227-240 (2006) 